\title{
A rare case report of Eagle's syndrome complicated with chronic mouth opening, its management and complete rehabilitation; dental perspective
}

\author{
A. Navin Kumar*, Bhushan Kumar, Gaurav Dua, Sandeep Mehta
}

Army Dental Corps, Pathankot, Punjab, India

Received: 29 September 2017

Revised: 13 November 2017

Accepted: 14 November 2017

\section{*Correspondence:}

Dr. A. Navin Kumar,

E-mail: dr.bhushansheoranmds@gmail.com

Copyright: (C) the author(s), publisher and licensee Medip Academy. This is an open-access article distributed under the terms of the Creative Commons Attribution Non-Commercial License, which permits unrestricted non-commercial use, distribution, and reproduction in any medium, provided the original work is properly cited.

\begin{abstract}
Eagle's syndrome is a rare condition of either elongated styloid process or ossification of its ligaments; which is less appreciated and often ignored condition by clinicians because of its vague symptoms which can be easily confused with other oral or paraoral conditions presenting with similar signs and symptoms. Since it is not a routine clinical problem, it is not given the first priority thought while diagnosing such a case; especially in the absence of sound clinical knowledge and good radiographs. This article is aimed to summarize unusual clinical presentations, diagnosis and standardized tonsil-sparing trans-oral surgical approach for Eagle's Syndrome case and its unique postoperative management. A 80 years old female patient presented with the tendency of uncontrolled wide mouth opening with severe pain in both ears, temporal region; submandibular area extending up to back of neck with intensity on right side. The patient was diagnosed as a case of the Eagle's syndrome with a unique finding of pain relief on wide mouth opening. The patient was operated for bilateral styloidectomy followed by postsurgical rehabilitation with custom made chin cup appliance and mouth opening exercises.
\end{abstract}

Keywords: Eagle syndrome, Styloidectomy, Elongated styloid process

\section{INTRODUCTION}

Patients with chief complain of pain in ear/ throat/ neck while jaw movements like in speech/ chewing/ swallowing or while various neck movements are quite often seen in Dental or ENT OPD and the clinicians start managing these cases as regular cranio-mandibular or oro-dental pathologies or ENT problems as per sign and symptoms. Until the patient is non-responsive to their treatment, the clinician hardly suspects for styloid process. ${ }^{1-5}$ In adults, the styloid process is approximately $25 \mathrm{~mm}$ long with its tip lying between the external and internal carotid arteries and is lateral to the pharyngeal wall and immediately behind the tonsillar fossa and approximation to nearby nerves (Embryological development justifies all these relationships). ${ }^{3,6,7}$ Such anatomic location of the styloid process is not permitting any variation in its anatomic shape/size without leading to pressure changes on these vital structures during movements of the neck and jaw. Any growth of styloid process or ossification of its ligaments (stylohyoid and stylomandibular ligament) causes elongation of the styloid process and depending on the position of the styloid process in relation to underlying anatomical structures, symptoms vary considerably and in rare cases, continuous compression of the carotid artery can lead to stroke and even death. Diagnosis can be made by a clinical examination and digital palpation of the tonsillar fossa, during which pain is felt by the patient. Detailed case history, clinical examination and radiographic investigations are the keys to diagnose Eagle's syndrome. $^{1-7} \quad 2 \mathrm{D}$ Imaging (ortho-pantomogram, 
posteroanterior skull view, lateral cephalogram, lateral oblique mandible view, modified Towne's view, and open mouth odontoid view) helps to identify the elongated styloid process or the calcified stylohyoid ligament. ${ }^{8,9}$ The advantage being, the entire length and any deviation are evident; however, superimpositions of anatomical structures frequently cause difficulties in viewing the styloid process. ${ }^{10,11} 3 \mathrm{D} \mathrm{CT}$ scan is the most valuable diagnostic tool because of its ability to facilitate accurate measurement of the length of the styloid process. ${ }^{12-14}$ Moreover, it can define its angulation, and anatomic relationship and thus outlining the plane of incision for surgical treatment. ${ }^{15}$

Surgical resection (styloidectomy) is accepted as the primary treatment modality in cases of Eagle's syndrome and several transoral and extraoral approaches have been described. ${ }^{16}$ The choice of access usually depends on the experience of the surgeon. ${ }^{17-19}$ In the majority of the cases, complete removal or surgical shortening of the elongated processes provides instant relief from troublesome symptoms. The intra-oral approach has some advantages such as the simplicity of the technique, reduced operating time, absence of visible scars, and minor risks of operative complications. ${ }^{20,21}$ Several pharmacological and conservative treatments are still being practiced like: analgesics and local corticosteroids or anesthetic administration (such as transpharyngeal anesthetics in the tonsillar fossa) has been suggested, but turned out to be non-effective. ${ }^{6,22}$ Infiltration of local anesthetics can be used as a proof therapy to see if a patient's complaints are related to an elongated styloid process.

\section{CASE REPORT}

80 years old female patient reported to ENT OPD for complains of severe pain in both ears for the last two years and after repeated examination was referred to the Dental Centre to rule out any TMJ pathology. Clinical examination revealed that patient had a tendency of uncontrolled excessive wide mouth opening with severe pain in both ears, temporal region; submandibular area extending up to back of neck with intensity on right side. A unique presenting feature was the pain relief on wide mouth opening with tongue protruding out and the patient had become habitual of this position; however, closing was difficult and painful. (Figure 1). The patient was completely edentulous and had not worn any prosthesis for 09 years. She had difficulty in swallowing. All these findings pointed towards TMJ pathology, but clinical examination of both TMJ's were asymptomatic. During intra-oral examination, when the clinician palpated in retromolar and the tonsillar region, the patient got severe pain. Clinical palpation under local anesthesia (glossopharyngeal nerve block) led to the finding of abnormally long styloid processes bilaterally. Patient was provisionally diagnosed as a case of Eagle syndrome and further radiographic investigation (orthopantomogram and non-contrast computed tomography) confirmed the clinical diagnosis (Figure 2). Considering the age and health of the patient, "trans-oral tonsil sparing" bilateral styloidectomy was performed under general anesthesia. Manual palpation of styloid process was carried out to get an idea for incision line. Layer wise dissection was performed for surgical exposure of the styloid process tip using cautery (Figure 3 ). The surgical instrument used to remove the styloid process was custom milled tool spanner with sharp internal edges and smooth outer surface fabricated in dental laboratory (Figure 4). The advantage of using this instrument was a thorough isolation of the styloid process by stripping of various attachments and self-retraction from its neighbouring vital structures while operating (Figure 5). Once the instrument had stripped off $2 / 3^{\text {rd }}$ of the styloid process, a lever movement was used to fracture it from base of skull, and gently pulled with a straight krocker. Same procedure was repeated on the opposite side (Figure 6). Post healing the patient was completely relieved of pain symptoms, but her habit of mouth opening along with difficulty in closing was still persisting. Post complete healing; a custom made chin cup with head support was given for 2 months and the patient was gradually trained to open and close mouth. Presently, the patient is asymptomatic and performing all routine life activities. She is under prosthetic rehabilitation process.

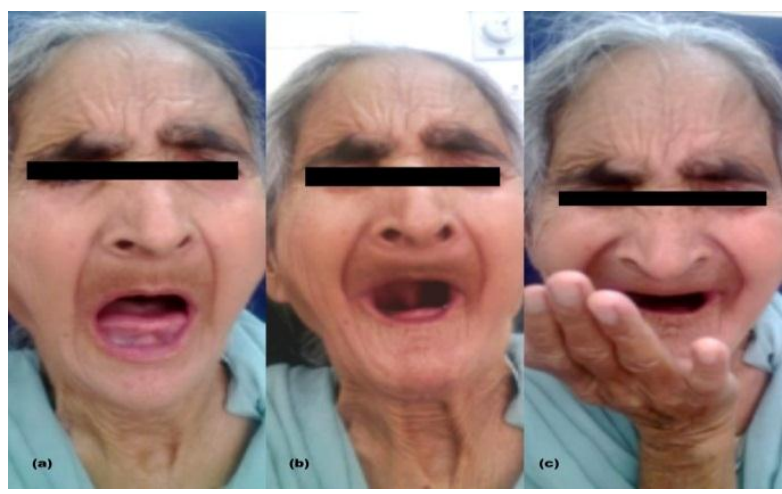

Figure 1: (a) Pain relief by excessive mouth opening, (b) difficulty in closing the mouth, (c) closure of mouth manually with pain and difficulty.

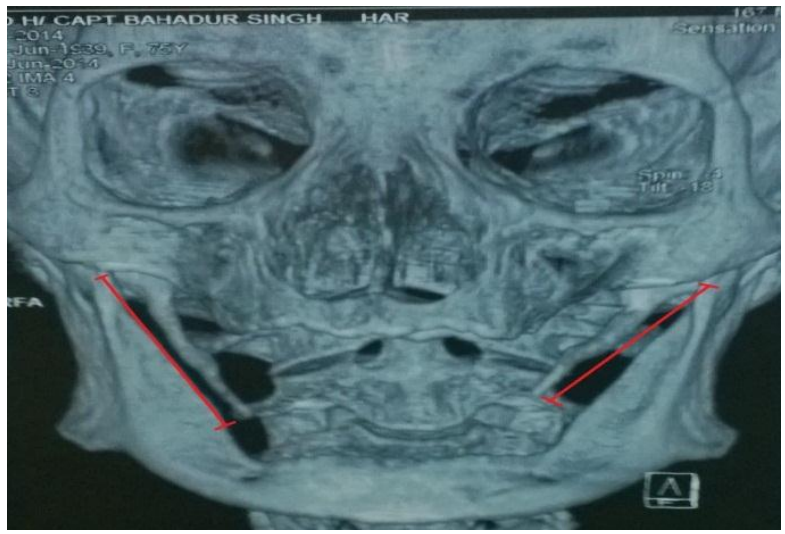

Figure 2: NCCT view showing elongated bilateral styloid processes. 


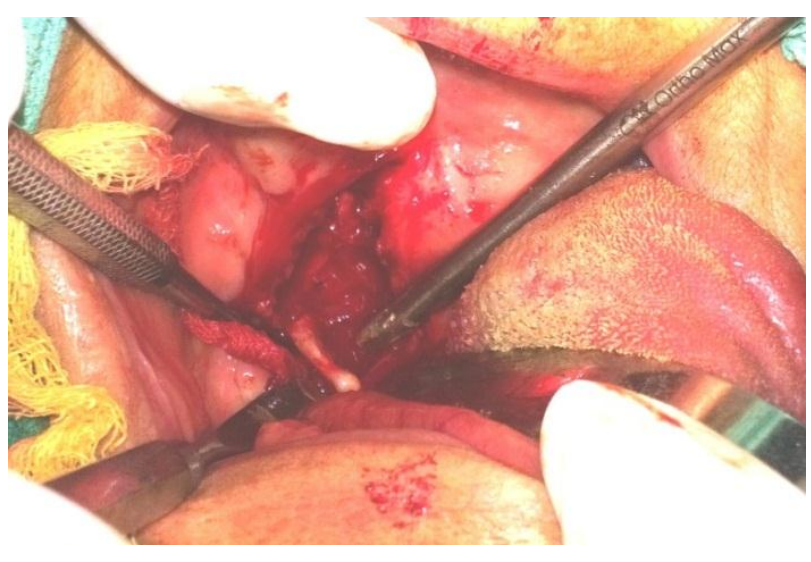

Figure 3: Surgical exposure of styloid process.

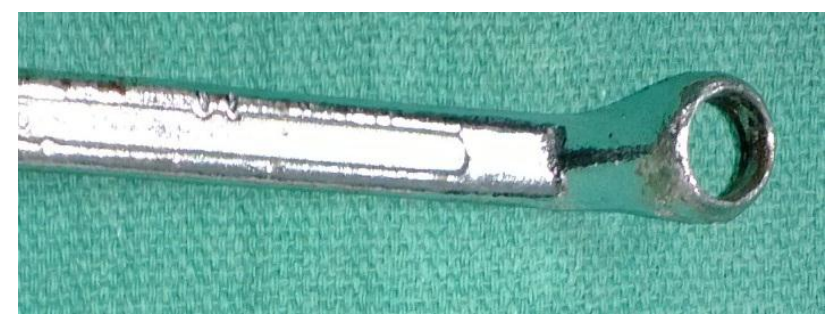

Figure 4: Custom milled spanner tool.

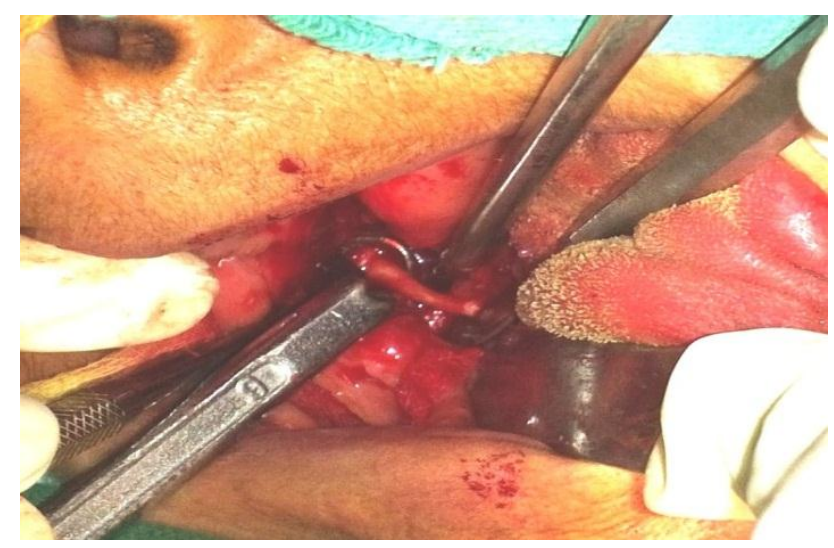

Figure 5: Use of custom milled spanner tool in surgery.

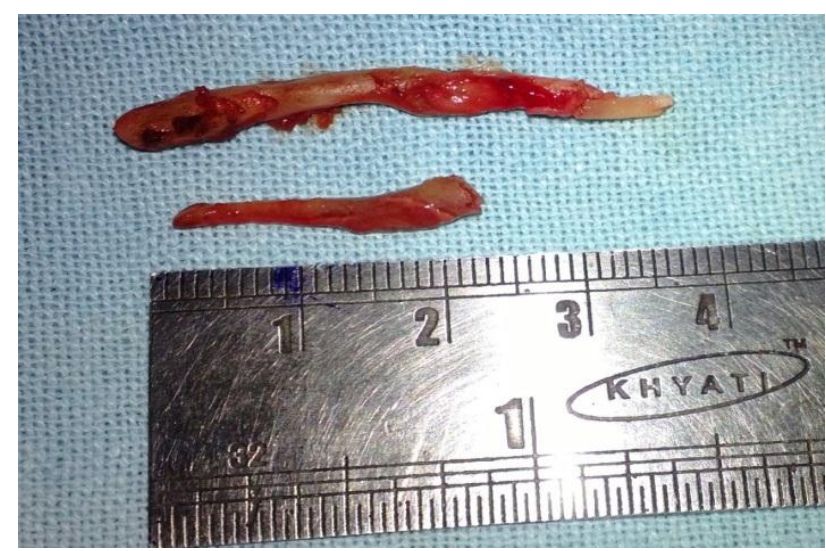

Figure 6: removed specimen of styloid processes.

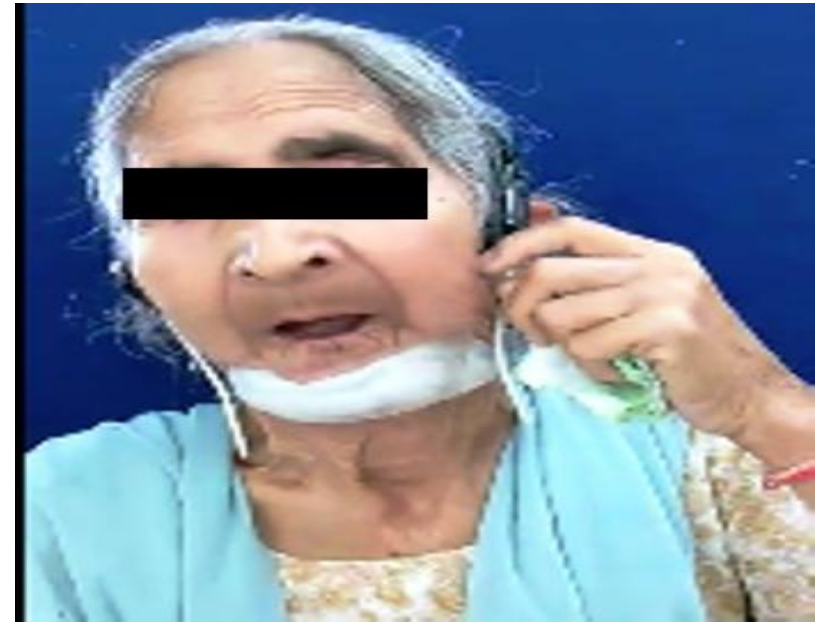

Figure 7: Custom fabricated chin cup with head gear support for postsurgical rehab.

\section{DISCUSSION}

The current case had presented all the symptoms of the Eagle's syndrome. An interesting finding was unusual habitual mouth opening with protrusion of the tongue as the patient had temporary pain relief by opening the mouth wide. Considering the patient age and health, the case was managed with bilateral styloidectomy using an intraoral tonsillar sparing approach (Complete Edentulism provides wide accessibility at the surgical site and is in favour of selecting this approach). ${ }^{20,22}$ The procedure was easy to execute, time saving and with good specificity. The exposure was adequate and the amount of dissection required was minimal. Custom designed instrument was not only effective in detaching styloid attachments, but also reduced chances of damage to nearby structures (like neurovascular damage, deep cervical infection, poor visualization of surgical field) to zero. $^{21,22}$ Same instrument was used to break the styloid process from its base. ${ }^{19,20}$ The patient got immediate relief from pain symptoms due to removal of pressure on the adjacent vital structures. As the patient had a wide mouth opening for a long time, so she developed this as uncontrolled habit and was persistent even postoperatively which led to muscle spasm in mouth opening muscles and was causing difficulty in mouth closing. After an extensive head strap supported chin cup therapy for minimum 10 hours/day at intervals along with opening and closing exercises for continuous 2 months helped in breaking habit and regaining muscle tonicity. (Figure 7).

\section{CONCLUSION}

Eagle's syndrome symptoms are not classical and can mimic those of other oral or para-oral disorders therefore this syndrome must also be included as differential diagnosis of patients with pain in the orofacial, pharyngeal, cervical area or other pathologies including temporo-mandibular joint, salivary gland, muscles, blood 
vessels, nerves, mucous membrane etc. The physician's knowledge of its possible clinical variations assisted with radiological confirmation can be very useful in early detection of this rare condition.

Funding: No funding sources Conflict of interest: None declared

Ethical approval: Not required

\section{REFERENCES}

1. Ferreira de Albuquerque R Jr, Mu“ ller K, Hotta TH, Gonçalves M. Temporomandibular disorder or Eagle's syndrome? A clinical report. J Prosthet Dent. 2003;90:317-20.

2. Eagle WW. Elongated styloid process: further observations and a new syndrome. Arch Otolaryngol. 1948;47:630-40.

3. Eagle WW. The symptoms, diagnosis and treatment of the elongated styloid process. Am Surg. 1962;28:1-5.

4. Dinkar, Amonkar SS. Eagle's syndrome: review of literature and case report. Indian $\mathbf{J}$ Dent Res. $2003 ; 14: 162-8$.

5. Soh KB. The glossopharyngeal nerve, glossopharyngeal neuralgia and the Eagle's syndrome--current concepts and management. Singapore Med J. 1999;40:659-65.

6. Ceylan A, Ko“ybasioglu A, Celenk F, Yilmaz O, Uslu S. Surgical treatment of elongated styloid process: Experience of 61 cases. Skull Base. 2008;18:289-95.

7. Rodríguez-Vázquez JF, Mérida-Velasco JR, Verdugo-López S, Sanchez-Montesinos I, Merida Velasco JA. Morphogenesis of the second pharyngeal arch cartilage (Reichert's cartilage) in human embryos. J Anat. 2006;208:179-89.

8. Miloro M. Fracture of the styloid process: A case report and review of the literature. J Oral Maxillofac Surg. 1994;52:1073.

9. Rezui-Marhoul L, Douira W, Saı̈d W, Bouslama K. Dridi MB, Hendaoui L. Le syndrome de Eagle: a` propos d'un cas. Rev Stomatol Chir Maxillofac. 2004;105:50-2.

10. Ghosh LM, Dubey SP. The syndrome of elongated styloid process. Auris Nasus Larynx. 1999;26:1695 .
11. Savranlar A, Uzun L, Ugur MB, Ozer T. Threedimensional CT of Eagle's syndrome. Diagn Interv Radiol. 2005;11:206-9.

12. Akhaddar A, Elasri A, Zalagh M, Boucetta M. Eagle's syndrome (Elongated styloid process). Intern Med. 2010;49:1259.

13. Karam C, Koussa S. Syndrome de Eagle: Eagle syndrome: the role of CT scan with 3D reconstructions. J Neuroradiol. 2007;34:344-8.

14. Dao A, Karnezis S, Lane JS 3rd, Fujitani RM, Sarem F. Eagle syndrome presenting with external carotid artery pseudoaneurysm. Emerg Radiol. 2011;18:263-5.

15. Andrade MG, Marchionni AM, Rebello IC, Martinez M, Flores PS, Reis SR. Three-dimensional identification of vascular compression in Eagle's syndrome using computed tomography: case report. J Oral Maxillofac Surg. 2008;66:169-76.

16. Diamond LH, Cottrell DH, Hunter MJ, Papageorge M. Eagle syndrome: A report of 4 patients treated using a modified extraoral approach. J Oral Maxillofac Surg. 2001;59(12):1420-6.

17. Beder E, Ozgursoy OB, Ozgursoy SK. Current diagnosis and transoral surgical treatment of eagle's syndrome. J Oral Maxillofac Surg. 2005;63:1742-5.

18. Messer EJM, Abramson AM. The styloid syndrome. J Oral Surg. 1975;33:664.

19. Sivers JE, Johnsoon GK, Lincoln MS. Diagnosis of Eagle's Syndrome. Oral Surg Oral Med Oral Pathol. 1985;59:575.

20. De Souza Carvalho AC, Magro Filho O, Garcia IR Jr. Intraoral approach for surgical treatment of Eagle syndrome. Br J Oral Maxillofac Surg. 2009;47:1534.

21. Chrcanovic BR, Custódio AL, de Oliveira DR. An intraoral surgical approach to the styloid process in Eagle's syndrome. Oral Maxillofac Surg. 2009;13:145-51.

22. Politi M, Toro C, Tenani G. A rare cause of cervical pain: Eagle's syndrome. Int J Dent. 2009;1-3.

Cite this article as: Kumar AN, Kumar B, Dua G, Mehta S. A rare case report of Eagle's syndrome complicated with chronic mouth opening, its management and complete rehabilitation; dental perspective. Int J Otorhinolaryngol Head Neck Surg 2018;4:297-300. 